ÓXIDO DE ETILENO COMO AGENTE ESTERILIZANTE:
CARACTERÍSTICAS GERAIS, TOXICIDADE E COMPARAÇÃO
COM OUTROS SANEANTES E MÉTODOS DE ESTERILIZAÇÃO

\title{
ETHYLENE OXIDE AS A STERILIZING AGENT: GENERAL CHARACTERISTICS, TOXICITY AND COMPARISON WITH OTHERS SANEANTES AND STERILIZATION METHODS
}

ANDRADE JÚNIOR, Francisco Patricio de ${ }^{1}$; ROMANO, Thalyta Karem Ferreira ${ }^{1}$; LIMA, Brenda Tamires de Medeiros*1; SOUZA, Élida Kaline Melo de'; ALVES, Thiago Willame Barbosa; SILVA, Isabela Bezerra da ${ }^{1}$; MORAIS, Maria Franncielly Simões de ${ }^{1}$; SOUZA, Júlia Beatriz Pereira de ${ }^{2}$.

1 Universidade Federal de Campina Grande, Centro de Educação e Saúde, Unidade Acadêmica de Saúde, Olho D'água da Bica S/N, cep 58175-000, Cuité - PB, Brasil.

(fone: +55 84 98135-7242)

${ }^{2}$ Prof $^{-}$Dr ${ }^{\underline{a}}$ da Universidade Federal de Campina Grande, Centro de Educação e Saúde, Unidade Acadêmica de Saúde, Olho D’água da Bica S/N, cep 58175-000, Cuité - PB, Brasil.

(fone: +55 83 99921-9976)

\author{
* Autor correspondente \\ e-mail: brendatamiresml@gmail.com
}

Received 29 June 2018; received in revised form 09 August 2018; accepted 10 August 2018

\section{RESUMO}

O gás óxido de etileno é altamente tóxico, facilmente inflamável e explosivo, sendo também carcinogênico, mutagênico, teratogênico e neurotóxico. Contudo, trata-se de um excelente esterilizante, sobretudo, quando aplicado a materiais médico-hospitalares termossensíveis. O presente estudo teve como objetivo realizar uma revisão bibliográfica sobre o óxido de etileno ressaltando suas características gerais, toxicidade e a comparação com outros métodos de esterilização. Trata-se de uma revisão narrativa, em que a recuperação de estudos ocorreu nas bases de dados Lilacs, Scielo, PubMed, Science Direct, Periódicos Capes e Bancos de Teses e Dissertações de Universidades Públicas. Foram recuperados 126 estudos, sendo que somente 43 foram utilizados para a construção deste trabalho. O óxido de etileno é caracterizado como um método físico-químico excelente, de fácil difusão e eficiência contra todos os microrganismos, desde que seja corretamente utilizado. Ao compará-lo com outros métodos de esterilização como autoclavação, PPH e VBTF, o óxido de etileno mostrou-se mais eficiente, a depender do tipo de material submetido ao processo de esterilização. Entretanto, devido sua capacidade de contribuir para o desenvolvimento de cânceres, principalmente do sistema linfohematopoiético, o seu desuso e desagrado por parte dos profissionais de saúde, serviços de saúde e empresas vem tornando-se frequente.

Palavras-chave: Óxido de etileno, esterilização, toxicidade.

\section{ABSTRACT}

Ethylene oxide gas is highly toxic, highly flammable and explosive. It is also carcinogenic, mutagenic, teratogenic and neurotoxic. However, it is an excellent sterilant especially when applied to thermally sensitive medical and hospital materials. The present study aimed to carry out a literature review on ethylene oxide emphasizing its general characteristics, toxicity and comparison with other methods of sterilization. This is a narrative review, in which the retrieval of studies occurred in the databases Lilacs, Scielo, PubMed, Science Direct, Periódicos Capes and Theses Banks and dissertations of the public universities. A total of 126 studies were retrieved, and only 43 were used for the construction of this work. Ethylene oxide is characterized as an excellent physicochemical method, easy to diffuse and efficient against all microorganisms, provided it is correctly used. Compared with other sterilization methods such as autoclaving, PPH and VBTF, ethylene oxide proved to be more efficient, depending on the type of material submitted to the sterilization process. However, 
due to its capacity to contribute to the development of cancer, mainly the lymphohematopoietic system, its disuse and displeasure by health professionals, health services and companies has become frequent.

Keywords: Ethylene oxide, sterilization, toxicity.

\section{INTRODUÇÃO}

Nos últimos anos, no que se diz respeito à área da saúde, houve um rápido e crescente desenvolvimento tecnológico, tanto das técnicas e procedimentos, quanto dos materiais médicohospitalares. Foram desenvolvidos produtos médicos de alta complexidade, de valores elevados e bastante onerosos para as instituições hospitalares e, devido à pressão para reduzir os custos, a reutilização destes produtos tornou-se prática comum. (SILVA; PINTO, 2005; SUNDIN, 2014; SUNDIN; MACHADO NETO, 2012).

Tecnologias de limpeza, desinfecção e esterilização foram desenvolvidas para tornar possível e segura a reutilização de instrumentais e equipamentos médico-hospitalares. Contudo, quando se trata de esterilização propriamente dita, esta pode ser conceituada como um método empregado para a utilização segura de produtos médicos em procedimentos diversos que promove eliminação ou destruição de todas as formas viáveis de microrganismos para um aceitável nível de segurança a fim de evitar possíveis infecções (MORIYA; MÓDENA, 2008; ASCARI et al., 2012; SUNDIN; MACHADO NETO, 2012).

Inúmeros são os métodos de esterilização difundidos e utilizados, dentre eles, tem-se a esterilização pelo óxido de etileno é amplamente usada em materiais médico-hospitalares com componentes plásticos ou termossensíveis que não resistem a temperaturas superiores a $60^{\circ} \mathrm{C}$ ou a processos de radiação.

Sintetizado por Wurtz em 1859 e utilizado desde a década de cinquenta do século passado, somente em 1992 o Ministério da Saúde autorizou a utilização do óxido de etileno como agente químico para esterilização, segundo a portaria 930/1992, denominando-o como saneante. Este é o mais antigo método de esterilização à baixa temperatura (PINTO; GAMOEDO, 2002; GOVEIA, PINHEIRO, GRAZZIANO, 2007; MORIYA, MÓDENA, 2008; SUNDIN, MACHADO NETO, 2012; SANTOS 2010).

O óxido de etileno é um gás liquefeito, incolor, altamente inflamável, tóxico e de composição química $\mathrm{C}_{2} \mathrm{H}_{4} \mathrm{O}$. É acondicionado em forma líquida pressurizado com nitrogênio e, em concentrações acima de 500 ppm, possui odor etéreo não residual. Além disso, é considerado um agente químico de alta eficácia que age à baixa temperatura devido ao seu poder de alta penetração e a capacidade destruição de microrganismos formadores de esporos (ABDO; RODRIGUES; FREITAS, 2010).

Por outro lado, a portaria no 482 retrata o gás óxido de etileno como altamente tóxico, facilmente inflamável e explosivo, sendo também carcinogênico, mutagênico, teratogênico e neurotóxico (BRASIL, 1999). Apresentando, portanto, desvantagens que devem ser consideradas.

Deste modo, levando em consideração a falta de publicações atuais que reúnam informações concisas acerca do óxido de etileno como agente esterilizante, o presente estudo teve como objetivo realizar uma revisão do tipo narrativa sobre o óxido de etileno ressaltando suas características gerais, toxicidade e a comparação entre outros métodos de esterilização.

\section{DESENVOLVIMENTO}

\subsection{Delineamento do estudo}

O presente estudo tratou-se de uma revisão bibliográfica do tipo narrativa. Houve a recuperação de artigos, livros, Portarias do Ministério da Saúde, monografias, dissertações e teses publicadas em língua portuguesa e inglesa, utilizando-se os delimitadores e palavras-chaves: 1) Óxido de etileno; 2) Esterilização; 3) Métodos de Esterilização; 4) Mecanismo de Ação; 5) Toxicidade; 6) Ethylene oxide; 7) Sterilization; 8) Methods of sterilization; 9) Mechanism of action; 10) Toxicity; utilizados isolados e associados em várias combinações.

\subsection{Critérios de inclusão e exclusão}

Foram incluídos estudos que em seu conteúdo trouxessem informações relevantes 
acerca da utilização do óxido de etileno como agente esterilizante, de artigo publicados durante os anos de 2000 a 2017. Estudos que não atenderam o tempo cronológico delimitado ou realizados com outros agentes esterilizantes sem que houvesse comparações com o óxido de etileno, foram excluídos. Desta forma, foram analisados 126 estudos, dos quais somente 43 foram utilizados para a construção desse artigo.

\subsection{Fontes de informação}

Os artigos foram recuperados a partir das bases de dados: Lilacs (Centro América Latina e Caribe em Ciências da Saúde), Scielo (Scientific Eletronic Library Online), PubMed, Science Direct, Periódicos Capes e Bancos de Teses e Dissertações de Universidades Públicas. O levantamento bibliográfico ocorreu entre abril e maio de 2018; a última atualização foi realizada em 13/05/2018.

\section{RESULTADOS E DISCUSSÃO:}

3.1. Características gerais relacionadas ao processo de esterilização utilizando o óxido de etileno

O estabelecimento de normas e de métodos de esterilização que sejam seguros são importantes para garantir não somente a melhor assistência à saúde, mas também para diminuir as infecções, sobretudo, em hospitais (BARBOSA; SARTORI, 2017).

O óxido de etileno (OE) é um dos agentes mais utilizados para a esterilização e reesterilização de materiais médico-hospitalares, principalmente os termossensíveis (GOVEIA et al., 2007; FUSCO; SPIRI, 2014).

A utilização do OE para fins esterilizantes em artigos médicos, se dá por método gasoso cuja a esterilização eficiente irá depender do contato direto desse gás com todas as superfícies do material (CAMARGO; FEITOSA; GRAZIANO, 2014). Entretanto, para poder ser utilizado, deve ser previamente misturado com gases inertes, para que o mesmo torne-se nãoinflamável e não-explosivo (CARVALHO, 2009).

O processo de esterilização utilizando este saneante é considerado um método físicoquímico e tornou-se uma das opções mais utilizadas para esterilização de materiais termossensíveis. Este gás apresenta concentração de $450 \mathrm{mg} / \mathrm{L}$ a $1200 \mathrm{mg} / \mathrm{L}$, além de ser utilizado em temperaturas de 45 a $60^{\circ} \mathrm{C}$ com uma umidade de 20 a $40 \%$, com tempo de exposição do material variando entre 2 a 5 horas (ARCHANJO, 2012).

Contudo, mesmo o OE sendo considerado eficiente na esterilização de materiais médico-hospitalares, a limpeza anterior a esterilização, no caso de materiais de reuso, é de grande valia, devido possibilitar a diminuição da carga microbiana, interferentes e contaminantes.

A limpeza pode ser realizada manualmente ou automatizada, de forma que sempre haverá a utilização de água e sabão. Para equipamentos e artigos médicos com muitas partes, estes devem ser desmontados para garantir que sua limpeza ocorra. A utilização de detergentes enzimáticos têm demonstrado sucesso como agentes limpadores de alta eficiência, por terem a capacidade de limpar satisfatoriamente sangue, pus e fluídos (SILVA et al., 2005).

O processo de esterilização com óxido de etileno normalmente inclui uma fase de précondicionamento ou condicionamento, seguida de vácuo para a retirada do ar do interior da câmara, entrada de gás inerte e agente esterilizante (óxido de etileno), exposição (fase de esterilização propriamente dita), lavagens com gás inerte e ar para remover resíduos de óxido de etileno e, por fim, uma aeração completa para eliminar o gás da carga (MORIYA; MÓDENA, 2008; SUNDIN, 2014).

A esterilização, propriamente dita, é realizada em um equipamento, no qual os produtos médicos, primeiramente embalados com invólucros de esterilização, são postos em cestos e em seguida submetidos à esterilização. Nesse processo, alguns parâmetros são controlados, dentre eles estão: o tempo, a temperatura, a umidade e concentração do óxido de etileno. Em seguida, os materiais são aerados no interior do equipamento, por um período de tempo estabelecido, submetidos a pulsos de ar comprimido e nitrogênio para remover o máximo possível de resíduos do óxido de etileno. No fim do processo de esterilização, os cestos que contém os materiais médicos são direcionados para uma sala de aeração ambiental, na qual os produtos permanecem, havendo a renovação do ar ambiente. Após um tempo pré-estabelecido, os materiais estão prontos para uso (SUNDIN, 2014). 
A Unidade de Esterilização (UE), deve garantir a eficácia do processo, de forma que os resíduos do óxido de etileno e de seus derivados, após a esterilização, reesterilização ou reprocessamento (BRASIL, 1999), não devem ultrapassar os valores especificados na tabela 1 .

Tabela 1. Limites máximos de resíduos em correlatos em ppm

\begin{tabular}{|c|c|c|c|}
\hline Correlatos & ETO* & $\mathrm{ETCH}^{\star \star}$ & ETG $^{\star \star \star}$ \\
\hline Implantes & & & \\
\hline Pequenos $(10 \mathrm{~g})$ & 250 & 250 & 5.000 \\
\hline $\begin{array}{l}\text { Médios }(>10- \\
\quad<1000 \mathrm{~g})\end{array}$ & 100 & 100 & 2.000 \\
\hline Grandes (>100g) & 25 & 25 & 500 \\
\hline $\begin{array}{l}\text { Dispositivos } \\
\text { intra-uterinos }\end{array}$ & 5 & 10 & 10 \\
\hline $\begin{array}{l}\text { Lentes intra- } \\
\text { oculares }\end{array}$ & 25 & 25 & 500 \\
\hline $\begin{array}{c}\text { Correlatos que } \\
\text { contatam a } \\
\text { mucosa }\end{array}$ & 250 & 250 & 5.000 \\
\hline $\begin{array}{l}\text { Correlatos que } \\
\text { contatam o } \\
\text { sangue }\end{array}$ & 25 & 25 & 250 \\
\hline $\begin{array}{l}\text { Correlatos que } \\
\text { contatam a pele }\end{array}$ & 250 & 250 & 5.000 \\
\hline $\begin{array}{l}\text { Esponjadas } \\
\text { cirúrgicas }\end{array}$ & 25 & 250 & 500 \\
\hline
\end{tabular}

Para a validação do processo, alguns microrganismos podem ser utilizados para permitir o monitoramento dos sistemas de esterilização a gás utilizando óxido de etileno, a exemplo do Bacillus atrophaeus. Neste procedimento, contamina-se algum artigo médico com o bacilo e o esteriliza, utilizando o saneante; após o processo, se for constatado a ausência de esporos, indica-se que a esterilização foi válida (GRUCHINSKI, 2014).

O OE tem demonstrado ser um eficiente esterilizante frente a diversos tipos de microrganismos, especialmente em instrumentos complexos ou sensíveis (SILVA et al., 2005) destacando-se instrumentos para uso intravenoso, aparelhos para monitorização invasiva, marca-passos, broncoscópios e eletrodos (CARVALHO, 2009). Ademais, esse agente demonstrou ser eficiente e biocompatível como agente esterilizante em implantes mamários de silicone (AZEVEDO; CRUZ; PINTO,
2006).

\subsubsection{Vantagens e desvantagens}

O óxido de etileno tem como vantagens: ser bactericida, esporocida e virucida; se faz esterilizante a baixas temperaturas; é facilmente removível; sua obtenção, armazenamento e manuseio são acessíveis; é capaz de esterilizar uma gama de instrumentos e equipamentos sem danificá-los; é um método de esterilização econômico, simples e seguro e o material a ser esterilizado pode ser estocado por um período de tempo prolongado (MORIYA; MÓDENA, 2008; BERTANI; OLIVEIRA; ALVERNAZ, 2008).

Contudo, algumas desvantagens podem ser elencadas como: o custo elevado quando o serviço de esterilização é terceirizado; tempo de exposição estendido, geralmente maiores que 12 horas; potenciais riscos para pacientes, funcionários e meio ambiente e o tempo de aeração, que pode variar de 6 horas a 7 dias, a depender da composição e tamanho dos artigos esterilizados, do sistema de aeração e do tipo de esterilização utilizados, por exemplo. Por se tratar de um gás inflamável e explosivo é necessária a existência de uma área projetada, de forma a promover um fluxo de trabalho eficiente, tecnologia e equipamentos adequados, bem como uma equipe treinada (MENDES; BRANDÃO; SILVA, 2012; WILSON; NAYAK, 2013).

\subsection{Toxicidade}

Devido sua aplicação em diversas atividades, o óxido de etileno, vem sendo utilizado em fabricação de produtos médicos, fumigação de pesticidas e esterilização em hospitais; mesmo sendo usado em processos fechados e automatizados, com geralmente níveis abaixo de 1 ppm, a maior exposição a este produto químico se dá em trabalhadores (principalmente em carga e descarga do material, coleta de amostras de produto e execução de serviços de manutenção), aumentando assim os riscos de intoxicação ocupacional (LAUDOU; HARRISON, 2016).

Grande parte dos dados de exposição ocupacional tem relação com a produção do óxido de etileno e seu uso na esterilização industrial e hospitalar (IARC, 2012). No âmbito da esterilização de materiais hospitalares, a exposição ao óxido de etileno ocorre na abertura 
de esterilizadores, transferência de itens recém esterilizados para área de aeração ou abastecimento, troca de tanques e pontos de descarga do gás (LAUDOU; HARRISON, 2016).

Ademais, reações em materiais poliméricos são observados quando estes entram em contato com o óxido de etileno, ocasionando a produção de substâncias tóxicas ou a permanência de resíduos nos materiais, podendo resultar em riscos reais e potenciais a saúde dos profissionais que o manuseiam e dos pacientes no qual estes serão utilizados (BRASIL, 1999; SOUSA et al., 2011). Além disso, é sabido que a exposição ao óxido de etileno pode causar o desenvolvimento de diversas enfermidades devido sua toxicidade (BRASIL, 1999; XELEGATI et al., 2006).

\subsubsection{Toxicocinética}

Por tratar-se de um gás, quando está em temperatura e pressão ambiente, a inalação é a via primária de exposição ao do óxido de etileno, podendo ser absorvido também por via tópica (mesmo com a pele intacta). E rapidamente absorvido pelo trato respiratório, e por possuir alta solubilidade no sangue, a absorção está diretamente relacionada com a taxa de ventilação e concentração de óxido de etileno no ar inspirado, sendo distribuído por todo o corpo após a absorção (OSLON, 2014; PAROD, 2014).

Após a absorção e distribuição, o OE é metabolizado através de reações de hidrólise, formando 1,2-etanodiol, hidroxiacetaldeído, ácido glicólico, ácido glioxílico, ácido fórmico, ácido oxálico, e dióxido de carbono ou por reações de conjugação com glutationa, havendo a produção de ácidos mercaptúricos. Ambas vias de metabolização estão diretamente relacionadas com a desintoxicação do paciente, tendo os produtos formados excretados na urina, havendo ainda uma parte do gás exalado sendo eliminado de forma inalterada na expiração. Uma das principais características do $\mathrm{OE}$ é sua capacidade de reagir com macromoléculas celulares, como por exemplo a Hemoglobina $(\mathrm{Hgb})$ e DNA, havendo assim a formação de adutos (Figura 1) (KIRMAN; HAYS, 2017)

Adutos de DNA e/ou proteínas formados através da reação com agentes químicos potencialmente mutagênicos podem ser utilizados como biomarcador de exposição e ter seus dados associados à estudos de carcinogênese (GARCIA, 2011).
A maioria destes biomarcadores de exposição podem ser dosados e identificados, por exemplo, através da combinação das técnicas de cromatografia líquida e espectrometria de massa (IARC, 2012). Entretanto, os adutos formados de hemoglobina são melhores indicadores gerais de exposição por serem mais estáveis, tendo em vista que adutos de DNA, por outro lado, podem ser reparados ou fixados como mutações, sendo medidas menos precisas de exposição. Com isso, diversos estudos evidenciam dados referentes ao risco de câncer para humanos expostos a este esterilizante, tendo principal relação com os cânceres do sistema linfohematopoiético, se destacando a leucemia e câncer do tecido linfático (USEPA, 2016).

Deste modo, o OE é considerado um agente causador de risco ocupacional para trabalhadores da área da saúde, tendo em vista - potencial cancerígeno que esta substância apresenta. A Agência Internacional de Pesquisas sobre Câncer (IARC) coloca o composto no grupo 1, ao qual pertencem os agentes que são carcinogênicos para humanos, havendo portanto, evidências suficientes para classificá-lo como tal (PARTANEN; MONGE; WESSELING, 2009; IARC, 2012). Suspeita-se que a exposição prolongada ao óxido de etileno pode contribuir para o desenvolvimento de tumores linfoides, linfoma não-Hodgkin, mieloma múltiplo e leucemia linfocítica crônica, além do câncer de mama (IARC, 2012).

\subsubsection{Toxicidade evidenciada em seres humanos e em modelos animais}

Estudos desenvolvidos em ratos demonstraram que com a exposição de aproximadamente $0,5 \mathrm{ppm}$, cerca de $100 \%$ do óxido de etileno inspirado é absorvido, e em concentrações mais elevadas, a percentagem absorvida diminui de 90\% (10 ppm) a 68\% (100 ppm) e cai para $36 \%$ a 1000 ppm. Já em seres humanos expostos a níveis que vão desde 0,1 a 10 ppm, são absorvidos em torno de $75-80 \%$ do óxido de etileno inspirado (PAROD, 2014).

Em casos de exposição aguda, o contato direto com o gás ocasiona em irritação nos olhos, mucosas e pulmões, não sendo possível basearse no odor como sinal de alerta de exposição excessiva, havendo também relatos de asma ocupacional posterior ao ocorrido. Com isso, frente a este tipo de exposição (aguda) ocorre o surgimento de sintomas relacionados a irritação 
no trato respiratório superior sob concentrações entre 200 a 400 ppm, e acima de 1000 ppm (superexposição) observa-se cefaleia, náuseas, dispneia, vômito, sonolência, fraqueza e falta de coordenação. O contato com o óxido de etileno líquido, por sua vez, pode causar queimaduras, irritação grave e dermatites, tendo a absorção minimizada pela rápida evaporação. Além disso, a presença de linfocitose pode ser encontrada em achados laboratoriais após a exposição aguda (OSLON, 2014; LAUDOU; HARRISON, 2016).

Efeitos carcinogênicos em humanos têm sido evidenciados, sendo a leucemia mais comumente observada em trabalhadores expostos cronicamente ao OE, enquanto que em modelos animais a toxicidade neurológica e reprodutiva tem estado presente (OSLON, 2014; LAUDOU; HARRISON, 2016). Contudo, em seres humanos a possibilidade de abortos ocasionadas pela exposição ao OE é relatada em estudos antigos, como o de Hemmini et al., (1982) que observaram uma frequência aumentada da ocorrência de abortos espontâneos entre trabalhadoras envolvidas em procedimentos de esterilização nos quais usavase o EO como agente esterilizante.

Devido ao alto potencial de desencadear toxicidade ocupacional ao óxido de etileno, a OSHA (Occupational Safety and Health Administration - EUA) regulamenta os limites de exposição permitidos no local de trabalho, para que não haja danos à saúde dos trabalhadores, em que deve ser de $1 \mathrm{ppm}\left(1,8 \mathrm{mg} / \mathrm{m}^{3}\right)$ no ar em um TWA (Time Weighted Average) de 8 horas. Em locais em que a exposição ocupacional de trabalhadores ao produto exceda o valor regulamentado, há a necessidade de supervisão médica. (OSLON, 2014).

\subsubsection{Mecanismo de toxicidade e medidas preventivas}

No mecanismo de toxicidade, o óxido de etileno reage diretamente com o DNA e proteínas, levando à morte celular, sendo potencialmente teratogênico, mutagênico e carcinogênico (OSLON, 2014). O OE atua como um agente alquilante direto em que pode atacar os sítios nucleofílicos das bases nitrogenadas do DNA para formar uma variedade de adutos. $O$ aduto de DNA mais abundantemente formado a partir da reação com o óxido de etileno é o N7(2-hidroxietil)guanina, que pode sofrer depurinação espontânea ou enzimática para formar sítios abásicos, causando consequente mutação (HUANG, 2011). Além disso o OE, apresenta a capacidade de reagir com a hemoglobina, formando 0 aduto $\mathrm{N}-(2-$ hidroxietil)valina (HEV) (RIVERO et al., 2009). Com isso, culminam evidências de que o potencial carcinogênico do óxido de etileno dá-se através de um mecanismo genotóxico (IARC, 2012).

Assim, medidas de prevenção aos riscos de exposição ocupacional do OE devem ser tomadas, de forma que os trabalhadores expostos devem estar equipados com EPIs (Equipamentos de Proteção Individual) adequados, tendo a substituição periódica de acordo com o tempo de utilização. Além disso, é necessário estabelecer programas de vigilância epidemiológica, incluindo a educação dos trabalhadores em relação aos efeitos adversos, padrões de higiene e segurança para o manuseio seguro do óxido de etileno, assim como, o monitoramento ambiental, biológico e descarte de resíduos tóxicos (RIVERO et al., 2009).

Todavia, torna-se relevante salientar a importância da organização e valorização de medidas educativas no sentido de alertá-los e instigá-los ao pensamento crítico e interpretativo, tornando-os conscientes e seguros da realidade vivenciada cotidianamente (COSTA et al., 2017).

\subsubsection{Diagnóstico laboratorial}

No que diz respeito ao diagnóstico e tratamento de pacientes intoxicados, é relevante considerar a consulta com um clínico toxicologista qualificado, o qual apresentará conhecimento hábil para identificar determinada intoxicação (YOUNG, 2014).

A partir de uma perspectiva ocupacional, é importante que haja um acompanhamento adequado diante dos trabalhadores expostos ao óxido de etileno. Tradicionalmente, o método mais comum para biomonitoramento é a medida dos metabólitos EO (na urina) ou dos adutos de EO (hemoglobina e DNA). No entanto, os estudos citogenéticos fornecem informações significativas em relação à toxicidade $(\mathrm{GHOSH}$; GODDERIS, 2016).

Além disso, é imprescindível que haja a realização de exames médicos periódicos que enfatizem os sistemas pulmonar, hematológico, neurológico e reprodutivo, bem como os olhos e a pele, os quais são os principais afetados (RIVERO et al., 2009). 


\subsection{Comparação com outros métodos e formas de esterilização}

No estudo de Batista Neto et al., (2010) foi observada a eficácia de diferentes métodos de esterilização frente a canetas de bisturi elétrico de uso único. Para o óxido de etileno foram analisadas 59 amostras pelo método de esterilização manual e 58 pelo método de esterilização automatizado. A probabilidade de falha na esterilização foi de $0,36 \%$ pelo método manual e 0,05\% pelo método automatizado. Já em um estudo feito por Münker et al., (2018) testou-se diferentes métodos de esterilização para dispositivos médicos a base de que são baseados em PMMA (Poli metacrilato de metila), um cimento ósseo utilizado para fixação de implantes de joelho e quadril. $O$ estudo demonstrou que a autoclave não foi eficiente para esterilização desses materiais, ao passo que o óxido de etileno, o plasma de gás peróxido de hidrogênio e a $\gamma$-irradiação foram métodos adequados para esterilização destes dispositivos.

No estudo de Snyder et al., (2017), por sua vez, foram avaliados três métodos de esterilização para duodenoscópios, onde resultou-se que não foram encontradas diferenças significativas entre desinfecção de alto nível padrão (DHSL), desinfecção de alto nível duplo (DHL) ou desinfecção de alto nível padrão seguida de esterilização por gás de óxido de etileno (HLD/ETO) para as contaminações bacterianas.

Um estudo realizado por Kiminami et al., (2017) demonstrou o impacto dos métodos de esterilização sobre seringas de baseadas em polímeros, passíveis de formação de proteínas e partículas. Nas seringas que foram esterilizadas a vapor ou que não foram esterilizadas, não foi observada a formação de partículas. Em contrapartida, as seringas que foram esterilizadas com óxido de etileno apresentaram um pequeno aumento na massa de partículas e agregados, demonstrando pouca qualidade $e$ segurança para este produto. Outro método de esterilização utilizado, o de radiação, promoveu a formação de radicais residuais nestes materiais

Bhatnagar et al., (2016) investigaram os efeitos de quatro métodos de esterilização sobre propriedades físico-químicas e morfológicas de polímeros de alguns dispositivos médicos. Estes métodos incluíram: óxido de etileno, peróxido de hidrogênio vaporizado, radiação gama e feixe de elétrons. Relacionando-se ao óxido de etileno, este promoveu uma degradação significativa dos polímeros. Os outros métodos também causaram alterações na estrutura dos polímeros, permitindo ressaltar que é importante conhecer a estrutura química dos compostos para realizar uma posterior esterilização.

Em estudo realizado por Santos et al., (2008) foi observado que o óxido de etileno juntamente com outras técnicas de esterilização, utilizados em trocartes de uso único, reprocessados após o primeiro uso em pacientes que foram submetidos à colecistectomia laparoscópica eletiva, encontrou resultados de esterilidade em $100 \%(\mathrm{~N}=28)$ das amostras, após a limpeza e esterilização por três métodos (óxido de etileno, vapor à baixa temperatura e formaldeído, e plasma de peróxido de hidrogênio), onde antes de sua esterilização bactérias (Staphylococcus spp., Haempophillus spp., Corynebacterium spp., Klebsiella spp., Peptococcus spp., Serratia mearcescens, Propionibacterium spp., Enterobacter spp., Sarcinia spp., Streptococcus spp. alfa hemolítico, Proteus spp., Escherichia coli e Bacillus spp.) e fungos (Candida spp., Rodothorulla spp.) foram encontrados em $46,5 \%$ das amostras $(\mathrm{N}=13)$, demostrando que as técnicas empregadas foram eficientes.

No estudo de Pinto et al., (2012), por sua vez, foi investigado nove sondas para vitrectomia de uso único (reprocessadas após o uso) reprocessadas, embaladas e esterilizadas, em seguida foram segmentadas em 979 unidades de $3,5 \mathrm{~cm}$ e semeadas em meio de cultura Tríptico de Soja (TSB), observando-se que houve crescimento microbiano em $57 \quad(5,8 \%)$ das unidades amostrais, sendo 25 esterilizadas por óxido de etileno, 16 por plasma de peróxido de hidrogênio e 16 por vapor á baixa temperatura e formaldeído, demostrando falha nas três técnicas aplicadas, dando destaque para a maior ineficiência do óxido de etileno, encontrando-se com maior prevalência, microrganismos como: Micrococcus spp., Staphylococcus coagulase negativa, Pseudomonas spp. e Bacillus subtilis.

Quando a esterilização por OE é comparada com o Plasma de Peródico de Hidrogênio (PPH) e Vapor de Baixa Temperatura de Formaldeído (VBTF), pode-se perceber que a primeira técnica apresenta incompatibilidade com produtos contendo celulose (papel, algodão e gaze), restringindo o seu uso e a segunda técnica utiliza uma grande quantidade de 
formaldeído que pode ser absorvido pelos artigos médico hospitalares, podendo haver incompatibilidade, ocorrendo ainda variação de temperatura e consequentemente deformação do material médico hospitalar (OLIVEIRA, 2000). Já o óxido de etileno é altamente penetrante, difuso e solúvel, não danificando os materiais médicohospitalares, sendo uma alternativa para os mais diversos materiais.

Para a esterilização de instrumental laparoscópico montado, o estudo de Camargo, Feitosa e Graziano (2014) concluiu que os princípios físicos do calor latente e da condução térmica promovem a possibilidade de segurança para autoclavação de tais materiais permanentes montados, diferente dos métodos gasosos, incluindo o óxido de etileno, ao qual tal conclusão não pode se aplicar, devido a necessidade de contato do agente esterilizante com toda a superfície do material a ser esterilizado.

Quando o óxido de etileno é comparado com outras técnicas de esterilização, é visto que essa técnica se sobressai, podendo ser empregado com segurança em muitos produtos médico-hospitalares, prolongando a vida útil desses materiais (SILVA et al., 2005). Entretanto, mesmo o OE sendo considerado bastante vantajoso em relação a outros métodos, encontra-se em processo de desuso devido sua capacidade cancerígena.

\section{CONCLUSÕES:}

O óxido de etileno é caracterizado como um método gasoso de grande eficiência considerado válido e seguro para a esterilização de uma ampla gama de materiais médicohospitalares, como materiais a base de silicone ou plástico, equipamentos com partes plásticas e metálicas e, sobretudo, materiais termossensíveis. Entretanto, esse tipo de esterilização tem demonstrando incompatibilidades com materiais feitos a base de polímeros.

Ao comparar o óxido de etileno a outros métodos, como autoclavação, PPH e VBTF, este por vezes torna-se mais interessante como esterilizante, contudo é coerente que observe-se as características do material que passará pelo processo de esterilização, já que o OE é capaz de formar substâncias tóxicas ao entrar em contato com polímeros.
Por fim, a segurança desse agente é motivo de preocupação já que é responsável pelo desenvolvimento de diversos tipos de cânceres, o que vem contribuindo para o seu desuso e desagrado por parte dos profissionais de saúde, serviços de saúde e empresas.

\section{REFERÊNCIAS:}

1. Abdo, N., Rodrigues, D.B., Freitas, M. I. P. In: APECIH, 2010, 166.

2. Archanjo, A. B., Toneto, D. S., Santiliano, F. C., Pereira Júnior, O. S., Almeida, B. R. PUBVET, 2012, 6, 18.

3. Ascari, R. A., Silva, O. M., Azevedo Júnior, L., Berlet, L. J., Maldaner, C.; Mai, S. Cidadania em Ação: Revista de Extensão e Cultura, 2012, 6.

4. Azevedo, J. C., Cruz, A. S., Pinto, T. J. A. Revista Brasileira de Ciências Farmacêuticas, 2006, 42, 263.

5. Barbosa, L. S., Sartori, M. R. K. Cadernos da Escola de Saúde, 2017, 5, 153.

6. Bertani, N. G., Oliveira,T.A.; Alvernaz, S. S. Rev. Edu. Meio Amb. E Saúde, 2008, 237.

7. Bhatnagar, D., Dube, K., Damodaran, V. B., Subramanian, G., Aston, K., Halperin, F., Mao, M., Pricer, K., Murthy, N. S., Kohn, J. Macromolecular Materials and Engineering, 2016, 301, 1224.

8. Brasil. Ministério da Saúde e Ministério do Trabalho e Emprego. Portaria Interministerial no 482, de 16 de abril de 1999. Dispõe sobre procedimentos de 70 instalações e uso do gás óxido de etileno e suas misturas em unidades de esterilização, 1999.

9. Camargo, T. C., Feitosa, A. S., Graziano, K. U. Revista SOBECC, 2014, 19, 200.

10. Carvalho, K. C. S. Estudo comparativo da relação custo-benefício do serviço de esterilização: serviço hospitalar versus empresa terceirizada. 2009. 77 f. Monografia (Pós-Graduação em Hotelaria Hospitalar) - Centro de Excelência em Turismo. Universidade de Brasília, Brasília, 2009.

11. Costa, J. M. S., Barbosa, M. L. L., Silveira, H. F., Ferreira, T. M. S., Oliveira, 
T. L., Alencar, M. V. O. B., Sousa, J. M. C., Cerqueira, G. S. Revinter, 2017, 10, 151.

12. Fusco, S. F. B., Spiri, W. Texto Contexto Enfermagem, 2014, 23, 433.

13. Garcia, C. C. M., Angeli, J. P., Freitas, F. P., Gomes, O. F., Oliveira, T. F., Loureiro, A. P., Di Mascio, P., Medeiros, M. H. J. Am. Chem. Soc. 2011, 9143.

14. Ghosh, M., Godderis, L. Mutation Research/Reviews in Mutation Research, 2016, 770, 91.

15. Goveia, V. R., Pinheiro, S. M. C., Graziano, K. U. Revista Latino-Americana de Enfermagem, 2007, 15, 376.

16. Gruchinski, D. D. Estudo da influência do substrato na atividade do Bacillus atrophaeus em indicadores biológicos autocontidos utilizados para monitorar sistemas de esterilização a óxido de etileno. 2014. $40 \mathrm{f}$. Trabalho de Conclusão de curso (Tecnologia em alimentos), Universidade Tecnológica Federal do Paraná. Campo Mourão, 2014.

17. Hemminki, K., Mutanen, P., Saloniemi, I., Niemi, M. L., Vainio, H. Br Med J (Clin Res Ed), 1982, 285, 1463.

18. Huang, C. J. Wu, C. F., Shih, W. C., Chen, M. F., Chen, C. Y., Chien, Y. C., Liou, S. H., Chiang, S. Y., Wu, K. Y. Toxicology Letters, 2011, 202, 243.

19. larc. Working Group on the Evaluation of Carcinogenic Risk to Humans. Monographs on the Evaluation of Carcinogenic Risks to Humanas. Lyon: International Agency for Research on Cancer, 2012, 400.

20. Kiminami, H., Krueger A. B., Abe, Y., Yoshino, K., Carpenter, J. F. Journal of Pharmaceutical Sciences, 2017, 106, 1007.

21. Kirman, C.R., Hays, S.M. Regulatory Toxicology and Pharmacology, 2017, 91, 72.

22. Mendes, G. C., Brandão, T. R. S., Silva, C. L. M. Woodhead Publising Limited, 2012, 96 .
23. Moriya, T., Módena, J. L. P. Assepsia e antissepsia: Técnicas de esterilização. Medicina-Ribeirão Preto, 2008, 41, 273.

24. Münker, T. J. A. G., Visfeijken, S. E. C. M., Mulder, C. S., Vespasiano, V., Becking, A. G., Kleverlaan, C. J., On behalf of the CranioSafe Group. Journal of The Mechanical Behavior of Biomedical Materials, 2018, 81, 172.

25. Batista Neto, S., Graziano, K. U., Padoveze, M. C., Kawagoe, J. Y. Revista Latino-Americana de Emfermagem, 2010, $18,7$.

26. Oliveira, C. O. Esterelização por óxido de etileno: estudo da efetividade esterilizante de misturas não explosivas e compatíveis com a camada de ozônio. 2000. 175 f. Dissertação (Mestrado em Farmácia e Medicamentos) - Universidade de São Paulo, São Paulo, 2000.

27. Parod, R. J. Ethylene Oxide. Encyclopedia of Toxicology, 2014, 2.

28. Partanen, T., Monge, P., Wesseling, C. Acta Médica Costarricense, 2009, 51, 205.

29. Pinto, F. M. G., Araújo, V. G. L., Souza, R. Q., Goveia, V. R., Missali, C. C., Luz, R. A., Graziano, K. U. Revista Escola Enfermagem USP, 2012, 46, 603.

30. Pinto, T.J.A., Gamoedo, L.H.C. Pharm. Technol., Ed. Bras., 2002, 6, 67.

31. Rivero, E., Piñero, S., Ruiz, S. G., Sousa, L., Rodríguez, M., Barrio, E., Delgado, V., Corralejo, B. C., Guevara, H. Salud de los Trabajadores [online]. 2009, 17, 22.

32. Santos, H. C. O. Validação do processo de esterilização por óxido de etileno para determinar o tempo de aeração em frascos enterais. 2010. 59 f. Dissertação (Mestrado em Ciências Farmacêuticas) Universidade Federal de Goiás, Goiânia, 2010.

33. Santos, V. S. E., Zilberstein, B., Possari, J. F., Santos, M. A. A., Quintanilho, A. G., Ribeiro Júnior, U. Surgical laparoscopy, endoscopy \& percutaneous techniques, 2008, 18, 468.

34. Silva, M. V., Pinto, T. J. A. Revista Brasileira de Ciências Farmacêuticas, 2005, 41, 189. 
35. Silva, R. M. S., Sandri, A. P. G., Nakano, V., Nishiyama, S. A. B. Revista Uningá, 2005, 4, 122.

36. Snyder, G. M., Wright, S. B., Smithey, A., Mizrahi, M., Sheppartd, M., Hirsch, E. B., Chuttani, R., Heroux, R., Yassa, D. S., Olafsdottir, L. B., Davis, R. B., Anastasiou, J., Bapat, V., Bidari, K., Pleskow, D. K., Leffler, D., Lane, B., Chen, A. Gold, H. S., Barttley, A. King, A. D., Sawhney, M. S. Gastroenterology, 2017, 153, 1025.

37. Sousa, C. S., Torres, L. M., Azevedo, M. P. F., Camargo, T. C., Graziano, K. U., Lacerda, R. A., Turrini, R. N. T. Revista da Escola de Enfermagem da USP, 2011, 45, 1249.

38. Sundin, M. S. Riscos na reutilização de produtos médicos esterilizados em óxido de etileno. 2014. 76 f. Dissertação (Mestrado em Engenharia Biomédica pelo Programa de Pós-Graduação em Engenharia Biomédica) - Universidade Tecnológica Federal do Paraná, Curitiba, 2014.

39. Sundin, M. S., Machado Neto, V. XXIII Congresso Brasileiro em Engenharia Biomédica, 2012, 3, 426.

40. USEPA. Evaluation of the Inhalation Carcinogenicity of Ethylene Oxide (CASRN 75-21-8) In Support of Summary Information on the Integrated Risk Information System (IRIS), 2016.

41. Wilson, A. J., Nayak, S. Anaesthesia \& Intensive Care Medicine, 2013, 14, 427.

42. Xelegati, R., Robazzi, M. L. C. C., Marziale, M. H. P., Haas, V. J. Revista Latina-Americano de Enfermagem, 2006, 14.

43. Young, G. B. Intoxication. In: STEIN, J. (Ed). Reference Module in Neuroscience and Biobehavioral Psychology. Amesterdã: Elsevier, 2014. 


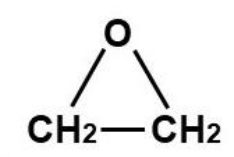

Óxido de Etileno

$(O E)$

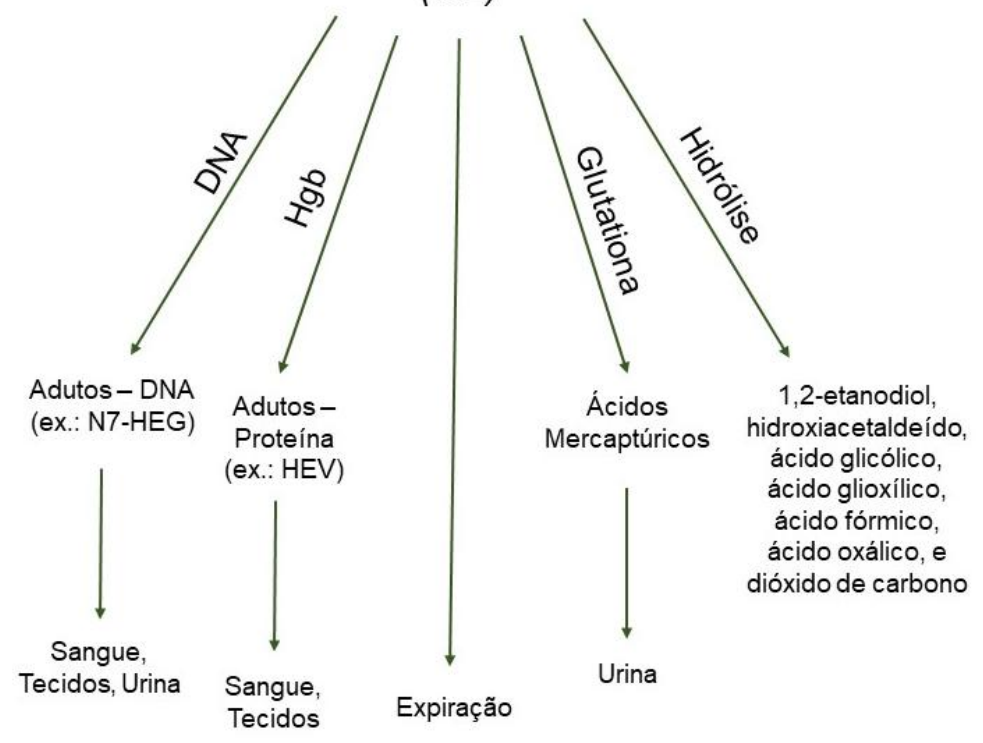

Figura 1. Metabolismo e biomarcadores para o óxido de etileno Fonte: Adaptado de KIRMAN; HAYS, 2017.

PERIÓDICO TCHÊ QUÍMICA • www.periodico.tchequimica.com • Vol. 16 N. 31.

- ISSN 1806-0374 (impresso) • ISSN 1806-9827 (CD-ROM) • ISSN 2179-0302 (meio eletrônico) (C) 2019. Porto Alegre, RS. Brasil

The Periódico Tchê Química (ISSN: 1806-0374; 2179-0302) is an open-access journal since 2004. Journal DOI: 10.52571/PTQ. http://www.tchequimica.com. This text was introduced in this file in 2021 for compliance reasons.

OPEN ACCESS. This article is licensed under a Creative Commons Attribution 4.0 (CC BY 4.0) International License, which permits use, sharing, adaptation, distribution, and reproduction in any medium or format, as long as you give appropriate credit to the original author(s) and the source, provide a link to the Creative Commons license, and indicate if changes were made. The images or other third-party material in this article are included in the article 's Creative Commons license unless indicated otherwise in a credit line to the material. If material is not included in the article's Creative Commons license and your intended
regulation or exceeds the permitted use, you will need to obtain permission directly from the copyright holder. To view a copy of this license, visit http://creativecommons.org/licenses/by/4.0/. 